\title{
Subsidized Monopolists and Product Prices: The Case of Major League Baseball
}

\author{
Phillip Miller ${ }^{\dagger}$
}

November 2006

\begin{abstract}
In this paper, I analyze the setting of ticket prices when teams receive subsidization from the public. I model teams as entertainment providers, where entertainment is generated by selling wins and amenities. I argue that subsidization of teams generally comes from subsidizing the amenities in and surrounding the teams' stadiums. Subsidization of the amenities lowers the marginal cost of providing them to fans and should drive ticket prices lower. The empirical analysis suggests that this is the case.
\end{abstract}

JEL Classification Codes: L83

Keywords: stadiums, baseball

*This report is an initial draft. Please do not quote, cite, or disseminate without the permission of the author. Any errors are solely my own.

${ }^{\dagger}$ Phillip A. Miller, Department of Economics, Morris Hall 150, Minnesota State University, Mankato, Mankato, MN 56001, E-mail: phillip.miller@mnsu.edu, Phone: 507-3895248. 


\section{Introduction}

When requesting public funds for a stadium that will house a sports team, stadium proponents often commission an economic impact statement: a study that attempts to show the effect that a new stadium will have on the local economy. Not surprisingly, these documents often amount to cheerleading and have been refuted by many independent researchers. Indeed, independent economists generally come to the conclusion that constructing a new sports stadium does not improve employment and wages in a local economy. For example, Baade and Dye (1990), Rosentraub, Swindell, Przybylski, and Mullins (1994), Baade (1996), Noll and Zimbalist (1997), and Coates and Humphreys (1999) and (2000) all conclude that professional sports are not net generators of economic activity. Other researchers have found that professional sports do provide intangible benefits to their local economies (for example, Carlson and Carlino (2003)), but some have estimated the value of the intangibles do not, by themselves, warrant full subsidization of a new stadium. For example, Johnson, Groothuis, and Whitehead (2001) argue that the value of public goods generated by the Pittsburgh Penguins is less than the cost of a new arena.

One area of attention that has not been given much attention is the effect of subsidies on general business decisions of sports teams, such as deciding how much to charge for admission to games. The ticket pricing strategies of professional sports teams has presented an interesting puzzle to analysts. Teams competing in the four major sports in the US (football, baseball, hockey, and basketball) each have some monopoly power in their home markets. If team owners maximize profits, they would price their tickets in 
the elastic portion of the fans' demand for the team’s product. Over the years, many researchers have found that, at least on average, team officials price tickets in the inelastic portion of their demand curves, suggesting that teams could raise ticket revenue by raising ticket prices. See Fort (forthcoming) for a nice summary of this literature. An explanation of this finding is that sports teams are not single-product producers but are, instead, the producer of many products. It may well be the case that teams set ticket prices in the inelastic portion of demand, leading to lower revenues from ticket sales than if they priced tickets higher. But this lost ticket revenue is more-than-made-up by sales of beer, soda, hot dogs, and other products (Sandy, Sloane, and Rosentraub (2004)).

While this explanation is quite plausible, it may be incomplete. If a profit-maximizing business owner receives a subsidy that lowers its marginal cost, it would rationally produce more output, but to sell it, it would have to offer the product at a lower price. If the subsidy is large enough, this could drive the business to price its product in the inelastic portion of its demand curve.

In this paper, I argue that sports teams produce entertainment for fans consume, entertainment is generated by performance on the field and amenities at the stadium. For example, at San Francisco’s AT\&T Park, the home of the San Francisco Giants of Major League Baseball, young fans can play on slides encased in a giant Coca Cola bottle and can play ball in a miniature stadium. While subsidies for sports teams generally are not designed to directly help the on-field performance of teams, they do affect the cost of providing amenities. In such cases, I argue that subsidies given to sports teams lower the 
marginal cost of providing entertainment and drive team officials to charge lower ticket prices than otherwise.

The rest of the paper is organized as follows: section 2 presents the theoretical model. Section 3 presents the empirical results. Section 4 concludes.

\section{Theory: Public Subsidies and Ticket Prices in Sports}

In most analyses of the demand for sports, authors develop models in which sports teams are assumed to maximize profits by producing wins (for example, see Fort and Quirk (1995) and Quirk and Fort (1992)). But recent empirical evidence by Alexander (2001) suggests that the pricing decisions made by sports teams are made with an eye towards the overall market for entertainment in their local cities.

Suppose that team “i” in an n-team league produces units of entertainment, $\mathrm{E}_{\mathrm{i}}$, which are then consumed by fans. Let units of entertainment be a function of the quality of the team, measured by its winning percentage, and the amenities at the ballpark. In sports within a league, the quality of a team is measured by its performance relative to the performance of the teams that it plays. For detailed examinations of the production of winning, I direct the interested reader to Fort and Quirk (1995) and to Szymanski (2003 and 2004). For brevity, I suppress the dependence of wins on the relative talent level for brevity, letting team winning percentage for team i be given by $w_{i}$. Note that $w_{i} \in[0,1]$ and $\sum_{i=1}^{n} w_{i}=1$ 
Amenities at a team's stadium or arena are also measured in units, $a_{i} \geq 0$. These amenities are generated by items such as concession stands, video replay boards, play areas for kids, and interactive games.

Suppose that the marginal cost of a win is constant at $\phi_{w}$. The cost of winning is thus $\phi_{w} w_{i}$. Amenities are also assumed to be exchanged in a competitive market at a price of $\phi_{a}$ yielding a cost for amenities of $\phi_{a} a_{i}$. The team's total cost of producing entertainment is thus given by $C_{i}\left(w_{i}, a_{i}\right)=\phi_{w} w_{i}+\phi_{a} a_{i} \cdot{ }^{1}$ Note that this cost function represents the costs of an unsubsidized team.

Let the demand for the team's entertainment be given by the twice continuouslydifferentiable function $P_{i}\left[E_{i}^{d}\left(w_{i}, a_{i}\right)\right] . E_{i}^{d}(\bullet)$ is a twice continuously-differentiable function that represents the number of units of entertainment demanded by fans. Entertainment is assumed to be increasing in its arguments. The team is assumed to have market power in the entertainment market, implying $\frac{\partial P}{\partial E_{i}^{d}}<0_{i}$. The second derivative of price with respect to entertainment is assumed to be zero. The second derivative of entertainment with respect to $w_{i}$ and $a_{i}$ is also assumed to be zero. Other demand factors, such as local population, per-capita income, fan expectations of team quality, and the prices of other entertainment options that affect the demand for entertainment are

\footnotetext{
${ }^{1}$ Since all other factors of production are treated as fixed, their costs are fixed and are ignored in this analysis.
} 
acknowledged but are, for simplicity, assumed to be constant and are thus suppressed in the notation.

The team's revenue function is given by $R_{i}\left(w_{i}, a_{i}\right)=P_{i}\left[E_{i}^{d}\left(w_{i}, a_{i}\right)\right] * E_{i}^{d}\left(w_{i}, a_{i}\right)$ and its profits are given by $\pi_{i}\left(w_{i}, a_{i}\right)=R_{i}\left(w_{i}, a_{i}\right)-C_{i}\left(w_{i}, a_{i}\right)=P_{i}\left[E_{i}^{d}\left(w_{i}, a_{i}\right)\right] * E_{i}^{d}\left(w_{i}, a_{i}\right)-\phi_{w} w_{i}-\phi_{a} a_{i}$. The team is assumed to maximize profits by choosing $w_{i}$ and $a_{i}$.

Let the team receive an exogenous per-unit subsidy of $s_{i}$ that goes towards paying for the amenities. Consider a team plays in a public stadium. If the local government picks up part of the tab of cleaning the bathrooms or providing security, this can be thought of as a subsidy for amenities ${ }^{2}$. In this case, the cost of providing the amenities becomes $\left(\phi_{a}-s_{i}\right) a_{i}$ and the team's profit function is $\pi_{i}\left(w_{i}, a_{i}\right)=R_{i}\left(w_{i}, a_{i}\right)-C_{i}\left(w_{i}, a_{i}\right)=P_{i}\left[E_{i}^{d}\left(w_{i}, a_{i}\right)\right] * E_{i}^{d}\left(w_{i}, a_{i}\right)-\phi_{w} w_{i}-\left(\phi_{a}-s_{i}\right) a_{i}$

The first-order conditions are given by

$\frac{\partial \pi_{i}\left(w_{i}, a_{i}\right)}{\partial w_{i}}=\frac{\partial P_{i}}{\partial E_{i}^{d}} \frac{\partial E_{i}^{d}\left(w_{i}, a_{i}\right)}{w_{i}} E_{i}^{d}\left(w_{i}, a_{i}\right)+P_{i}\left[E_{i}^{d}\left(w_{i}, a_{i}\right)\right] \frac{\partial E_{i}^{d}\left(w_{i}, a_{i}\right)}{w_{i}}-\phi_{w}=0$

${ }^{2}$ Subsidies to sports teams are often grouped into three different categories: construction and landacquisition subsidies (which include indirect subsidies of financing construction as discussed by Zimmerman (1997)), infrastructure subsidies, and operating subsidies. I make no distinction regarding the type of subsidy in the paper. The interested reader is directed to Long (2005), who meticulously calculates the subsidies received by teams in the 4 major American sports. 
and

$$
\frac{\partial \pi_{i}\left(w_{i}, a_{i}\right)}{\partial a_{i}}=\frac{\partial P_{i}}{\partial E_{i}^{d}} \frac{\partial E_{i}^{d}\left(w_{i}, a_{i}\right)}{a_{i}} E_{i}^{d}\left(w_{i}, a_{i}\right)+P_{i}\left[E_{i}^{d}\left(w_{i}, a_{i}\right)\right] \frac{\partial E_{i}^{d}\left(w_{i}, a_{i}\right)}{a_{i}}-\left(\phi_{a}-s_{i}\right)=0
$$

Note that the second-order conditions are satisfied by the assumptions. (1) therefore implicitly defines team winning percentage and (2) implicitly defines the level of amenities chosen by the team. Comparative static analysis yields that the level of amenities is increasing in the subsidy level which, in turn, yields a higher level of entertainment offered by the team and, thus, a lower price ${ }^{3}$.

Intuitively, subsidization lowers the marginal cost of providing entertainment, giving an incentive for teams to provide more entertainment. But in order to give fans an incentive to purchase more entertainment, team officials must set lower ticket prices. We now move to the empirical section

\section{The Empirical Model, The Data, and The Empirical Results}

In this section I explore the question of ticket setting under subsidization. In the theory, a team that is subsidized will set its ticket price lower than otherwise. To explore the

${ }^{3}$ Define FOC (2) as $G=\frac{\partial P_{i}}{\partial E_{i}^{d}} \frac{\partial E_{i}^{d}\left(w_{i}, a_{i}\right)}{a_{i}} E_{i}^{d}\left(w_{i}, a_{i}\right)+P_{i}\left[E_{i}^{d}\left(w_{i}, a_{i}\right)\right] \frac{\partial E_{i}^{d}\left(w_{i}, a_{i}\right)}{a_{i}}-\left(\phi_{a}-s_{i}\right)$. Then $\frac{\partial a}{\partial s}=-\frac{G_{s}}{G_{a}}$ by the implicit function rule. $G_{s}=1$ and $G_{a}<0$ since $G_{a}$ is the second-order condition. Therefore, $\frac{\partial a}{\partial s}>0$. Since entertainment is increasing in amenities and price is decreasing in entertainment, higher subsidies yield lower prices charged by the team. 
relationship between subsidization and pricing, I use data from Major League Baseball (MLB) during the period 1991-2003 and explore versions of the general model

$$
P_{i}=X_{i} \beta+s_{i} \gamma+\varepsilon_{i}
$$

which describes the relationship between the price team i charges for its tickets and its determinants. $\mathrm{P}_{\mathrm{i}}$ is the logarithm of real team ticket price published by the Team Marketing Report (TMR) database and obtained from Rod Fort's website. Each ticket price reported by TMR represents the weighted average price of tickets reported by teams. For each team, TMR researchers take ticket prices for each section in each team's stadium and weight them by the number of seats in each section. This weighted average series therefore controls for differences in seat quality throughout a stadium.

$\mathrm{X}_{\mathrm{i}}$ represents various factors that determine the demand for the entertainment provided by the team and the unsubsidized marginal cost of providing entertainment. The variables included in the $\mathrm{X}_{\mathrm{i}}$ matrix are

1. Logarithm of team attendance

2. A dummy equal to one for teams that made the playoffs in the previous season either as a division winner or, in or after 1994, as a wild card team

3. The previous season's team winning percentage

4. The age of the stadium (entered quadratically)

5. The logarithm of employment in the team's local SMSA's market

6. The logarithm of real per-capita income in the team's local SMSA's market 
All monetary values are in real 2003 dollars and were adjusted using the CPI for all urban consumers. All team productivity data was obtained or calculated from the Sean Lahman database (http://www.baseball1.com). Employment and per-capita income was obtained from the regional economic information system (REIS) database published by the Bureau of Economic Analysis. Stadium age information was obtained at various stages of the project from which this paper was developed from http://www.ballparks.com and http://www.ballparksofbaseball.com. I also include dummy variables for each of the years during the sample period. 2003 is the reference year for the dummies.

During the sample period, four expansion teams (Colorado and Florida in 1993 and Arizona and Tampa Bay in 1998) began play. For each of these teams in their expansion year, lagged winning percent values are missing. To be able to include these records in the analysis, I set lagged winning percentage equal to 0.400 . I based this value on the performance of expansion teams in 1977, 1993, and 1998. In doing so, I assume that fans of expansion teams expect their new teams will win $40 \%$ of their games in their expansion seasons ${ }^{4}$.

$\mathrm{s}_{\mathrm{i}}$ represents the subsidy provided to the team. As a proxy for subsidization, I include the proportion of the team's stadium that is privately-owned. While rough, teams playing in publicly-owned stadiums will have much of the upkeep of stadium amenities picked up by the public body that owns the stadium while teams that own their own stadiums will

\footnotetext{
${ }^{4}$ In 1977, Toronto and Seattle had an average winning percentage of 0.365. In 1993, Colorado and Florida had an average winning percentage of 0.404. In 1998 Tampa Bay and Arizona had an average winning percentage of 0.395. Since the sample period covers 1991-2003, I placed greater weight on the performances of the 1993 and 1998 expansion teams.
} 
generally have to provide their own maintenance. Additionally, private ownership proportion controls for the proportion of the team's stadium construction cost that was paid through public sources (the correlation between proportion of the stadium owned by the public ownership and the proportion of original construction costs paid by the public is 0.5618 which has a p-value of less than 0.0001 ). Since the construction subsidy's effect on team ticket prices will diminish over time, I have included this variable interacted with the age of the stadium.

$\beta$ and $\gamma$ are vectors of parameters to be estimated. $\varepsilon_{\mathrm{i}}$ is a random error term. Ticket prices are set between seasons with an eye towards the expected demand for tickets. To the extent that team officials properly estimate demand, team attendance and team ticket prices will be simultaneously-determined. Consequently, I estimate the models using two-stage least squares fixed effects and random effects models, estimating the logarithm of team attendance in the first stage using team winning percentage as an instrument.

Table 1 provides the summary statistics. Table 2 provides the regression results. In terms of significance and the values of the estimated parameters, both models produce similar results. Consequently, I will describe the results for the two models at once. The parameter estimate for team attendance is negative but insignificant. The previous season's winning percentage is positively correlated with team ticket prices and highly significant. The better a team performs, the higher its ticket prices will be next season. The playoff dummy had a positive relationship with team ticket prices, but the effect was not significant suggesting that whether a team makes the playoffs adds no additional 
explanatory power. The parameter for stadium age is negative but highly significant suggesting that as a team's stadium ages, its ticket prices fall. But the positive and significant parameter for the stadium age's quadratic term suggests that the fall diminishes over time. This result is plausible because new stadiums generate interest among the population. Initially, some locals who do not usually attend games will attend to see the new ballpark. But the existence of a new ballpark is unlikely to alter these locals’ preferences for sports. So the impact of a new ballpark on attendance drops off over time.

The parameter on the logarithm of employment is negative and significant suggesting that the higher the level of employment in a city, the lower the home team's attendance will be. Real per-capita income has a positive estimated coefficient, but the estimate is insignificant. The time dummies d1991 to d2001 are all negative suggesting that team ticket prices were lower during these years relative to 2003. Each of these dummies was significant except for d2000 and d2001. The coefficient on d2002 was positive and insignificant. These results suggesting that after controlling for other factors, ticket prices for the average team did not vary significantly between 2000 and 2003.

The parameter estimate on the age-private ownership proportion interaction term is positive and significant in both models. These results back up the theoretical results: teams that play in public stadiums, on average, charge lower ticket prices.

\section{Conclusion}


In this paper, I have analyzed the setting of ticket prices when teams receive subsidization from the public. I model teams as entertainment providers, where entertainment is generated by selling wins and amenities. I argue that subsidization of teams generally comes from subsidizing the amenities in and surrounding the teams’ stadiums. Subsidization of the amenities lowers the marginal cost of providing them to fans and should drive ticket prices lower. The empirical analysis suggests that this is the case.

One thing that I do not advocate in this paper is the giving of subsidies to sports teams. Indeed, the question of whether subsidies should be given depends on the public goods qualities of sports teams, their value, and the distortions that come from giving subsidies and imposing taxes to pay for them. However, this paper does shed light on the effect that subsidies have on the prices paid by fans. 


\section{Bibliography}

Alexander, Donald L. (2001); “Major League Baseball: Monopoly pricing and profitmaximizing behavior.” Journal of Sports Economics 2. 341-355

Baade (1996), Professional Sports as Catalysts for Metropolitan Economic Development, Journal of Urban Affairs 18, 1-17

Baade and Dye (1990), The Impact of Stadiums and Professional Sports on Metropolitan Area Development, Growth and Change 21, 1-14

Ballparks of Baseball http://www.ballparksofbaseball.com/

Carlson Gerald and Carlino, N. Edward (2003), “Compensating Differentials and the Social Benefits of the NFL.” Working Paper No. 02-12/R, Federal Reserve Bank of Philadelphia

Coates and Humphreys (1999), The Growth Effects of Sports Franchises, Stadia, and Arenas, Journal of Policy Analysis and Management 18, 601-624

Coates and Humphreys (2003) , “The Effect of Sports on Earnings and Employment in the services and retail sectors in U.S. Cities” Regional and Urban Economics 33. 175-198.

Fort, Rodney. Forthcoming. "Inelastic Pricing At the Gate? A Survey." In Wladimir Andreff, Jeffrey Borland, and Stefan Szymanski (eds.) The Handbook on the Economics of Sport (Northampton, MA: Edward Elgar Publishing, Inc.).

Fort, Rodney and James Quirk (1995), “Cross-Subsidization, Incentives, and Outcomes in Professional Team Sports Leagues,” The Journal of Economic Literature 33:3 1265-1299 
Johnson, Bruce K. Peter A. Groothuis, and John C. Whitehead (2001) “The Value of Public Goods Generated by a Major League Sports Team: The CVM Approach” Journal of Sports Economics 2, 6-21

Lahman, Sean “The Baseball Archive” http://www.baseball1.com/

Long, Judith Grant (2005): “The real cost of public funding for Major League sports facilities: Journal of Sports Economics 6:2. 119-143

Munsey and Suppes http://www.ballparks.com/

Noll, Roger and Andrew Zimbalist (1997), Sports, Jobs, and Taxes, Brookings Institution

Quirk, James and Rodney D. Fort (1992), Pay Dirt, Princeton University Press, Princeton, New Jersey

Rosentraub, Swindell, Przybylski, and Mullins (1994), Sport and Downtown Development Strategy: If You Build It, Will Jobs Come?, Journal of Urban Affairs 16, 221-239

Sandy, Robert, Peter J. Sloane, and Mark S. Rosentraub (2004). The economics of sport - an international perspective. Palgrave MacMillan, Houndmills, Basingstoke, Hampshire

Zimmerman, Dennis (1997), “Subsidizing Stadiums: Who Benefits, Who Pays?” in Sports, Jobs, and Taxes, (Andrew Zimbalist and Roger Noll ed.s) Brookings Institution 


\section{Table 1 - Summary Statistics}

$\begin{array}{lcc}\text { Team Winning } & \text { Mean } & \text { Std. Error } \\ \text { Percentage } & 0.50005 & 0.00389 \\ \text { Attendance } & 2246401 & 38804.9 \\ \text { SMSA Population } & 5445656 & 243593 \\ \text { Age of Stadium } & 29.0925 & 1.32235 \\ \begin{array}{l}\text { Real Per-capita } \\ \text { Income }\end{array} & 33928.7 & 243.04 \\ & & \\ \text { n } & 346 & \end{array}$




\section{Table 2 - Longitudinal IV Regression Results}

\begin{tabular}{|c|c|c|}
\hline & Fixed Effects & $\begin{array}{c}\text { G2SLS } \\
\text { Random } \\
\text { Effects }\end{array}$ \\
\hline Log of Attendance & $\begin{array}{c}-0.0142384 \\
0.0827991\end{array}$ & $\begin{array}{c}-0.0121995 \\
0.0793837\end{array}$ \\
\hline \multirow[t]{2}{*}{$\begin{array}{l}\text { Made Playoffs Last } \\
\text { Year }\end{array}$} & 0.0147519 & 0.0147713 \\
\hline & 0.0216629 & 0.020794 \\
\hline \multirow[t]{2}{*}{$\begin{array}{l}\text { Last Year's Winning } \\
\text { Percentage }\end{array}$} & $0.5799994 * * *$ & $0.5749689 * * *$ \\
\hline & 0.1701068 & 0.162093 \\
\hline Stadium Age & $\begin{array}{c}-0.0130373 * * * \\
0.0021137\end{array}$ & $\begin{array}{c}-0.0129904 * * * \\
0.0020148\end{array}$ \\
\hline \multirow[t]{2}{*}{$\begin{array}{l}\text { Stadium Age } \\
\text { Quadratic Term }\end{array}$} & $0.0001132 * * *$ & $0.0001129 * * *$ \\
\hline & 0.0000282 & 0.0000268 \\
\hline Log of Employment & $\begin{array}{c}-0.5608607^{* *} \\
0.2938196\end{array}$ & $\begin{array}{c}-0.4697361^{*} \\
0.2526121\end{array}$ \\
\hline \multirow[t]{2}{*}{$\begin{array}{l}\text { Log of Real Per- } \\
\text { capita Income }\end{array}$} & 0.3192887 & 0.2754194 \\
\hline & 0.3151844 & 0.2975824 \\
\hline \multirow{3}{*}{$\begin{array}{l}\text { Age-Private } \\
\text { Ownership } \\
\text { Proportion } \\
\text { Interaction }\end{array}$} & & \\
\hline & $0.0174526^{* * *}$ & $0.016732 * * *$ \\
\hline & 0.0047122 & 0.004 \\
\hline
\end{tabular}




\section{Table 2 Continued}

\begin{tabular}{|c|c|c|}
\hline d1991 & $\begin{array}{c}-0.3672653^{* * *} \\
0.0659605\end{array}$ & $\begin{array}{c}-0.3620675^{* * *} \\
0.0615759\end{array}$ \\
\hline d1992 & $\begin{array}{c}-0.3815554 * * * \\
0.0646528\end{array}$ & $\begin{array}{c}-0.3749953 * * * \\
0.059855\end{array}$ \\
\hline d1993 & $\begin{array}{c}-0.3435048 * * * \\
0.0621485\end{array}$ & $\begin{array}{c}-0.3383662 * * * \\
0.0584377\end{array}$ \\
\hline d1994 & $\begin{array}{c}-0.3040122 * * * \\
0.066051\end{array}$ & $\begin{array}{c}-0.2992078 * * * \\
0.0613153\end{array}$ \\
\hline d1995 & $\begin{array}{c}-0.3237078 * * * \\
0.0611957\end{array}$ & $\begin{array}{c}-0.3201026 * * * \\
0.0570326\end{array}$ \\
\hline d1996 & $\begin{array}{c}-0.2950087 * * * \\
0.0497122\end{array}$ & $\begin{array}{c}-0.2926634 * * * \\
0.0467142\end{array}$ \\
\hline d1997 & $\begin{array}{c}-0.235759 * * * \\
0.0425841\end{array}$ & $\begin{array}{c}-0.2343959 * * * \\
0.0402949\end{array}$ \\
\hline d1998 & $\begin{array}{c}-0.1560082^{* * *} \\
0.0334046\end{array}$ & $\begin{array}{c}-0.1547268^{* * *} \\
0.0318339\end{array}$ \\
\hline d1999 & $\begin{array}{c}-0.0764365^{* *} \\
0.0312442\end{array}$ & $\begin{array}{c}-0.0761792^{* *} \\
0.0299378\end{array}$ \\
\hline d2000 & $\begin{array}{c}-0.0360421 \\
0.030972\end{array}$ & $\begin{array}{c}-0.036143 \\
0.0297107\end{array}$ \\
\hline d2001 & $\begin{array}{c}-0.0155148 \\
0.0307996\end{array}$ & $\begin{array}{c}-0.0160824 \\
0.0295331\end{array}$ \\
\hline d2002 & $\begin{array}{c}0.0059267 \\
0.0300199\end{array}$ & $\begin{array}{c}0.0058686 \\
0.0287893\end{array}$ \\
\hline _cons & $\begin{array}{l}7.78006 \\
4.788311\end{array}$ & $\begin{array}{l}6.861296 \\
4.302186\end{array}$ \\
\hline $\mathbf{n}$ & 346 & 346 \\
\hline R-Squared & & \\
\hline within & 0.7674 & 0.7677 \\
\hline between & 0.0286 & 0.0458 \\
\hline overall & 0.1222 & 0.1566 \\
\hline sigma_u & 0.47533284 & 1.904567 \\
\hline sigma_e & 0.11210553 & 0.11210553 \\
\hline $\begin{array}{l}\text { rho (fraction of } \\
\text { variance due to } \mathbf{u} \text { _i) }\end{array}$ & 0.94730743 & 0.99654729 \\
\hline $\begin{array}{l}F \text { test that all } \mathbf{u}_{-} \mathbf{i}=\mathbf{0} \text { - } \\
\mathbf{F}(27,298)\end{array}$ & 10.58 & \\
\hline
\end{tabular}

